\title{
Lengths and Patterns
}

of Transcriptional Units

in the Amplified Nucleoli

of Oocytes of Xenopus laevis

\author{
Ulrich Scheer, Michael F. Trendelenburg, Georg Krohne, \\ and Werner W. Franke
}

Division of Membrane Biology and Biochemistry, Institute of Experimental Pathology,

German Cancer Research Center, D-69 Heidelberg, Federal Republic of Germany

\begin{abstract}
Transcriptionally active chromatin from peripheral amplified nucleoli of lampbrush-chromosome stage oocytes of Xenopus laevis was dispersed and spread in various solutions of low salt concentrations (including some with additions of detergents) and examined by electron microscopy. Nucleolar material from oocytes of animals with normal (2-nu) and mutant (1-nu) genetical constitution of nucleolus organizers was compared. Histograms showing the distributions of the lengths of matrix units, apparent spacer intercepts, and the total repeating units of the rDNA containing chromatin axes revealed a significant degree of heterogeneity, with indications of subclasses and predominant repeat unit size classes of 3.3 and $3.8 \mu \mathrm{m}$ length. The correspondence of matrix unit length to the molecular weight of the first stable product of rDNA transcription was studied using gel electrophoresis of labelled pre-rRNA under non-denaturing and denaturing conditions. Evaluations of individual strands of nucleolar chromatin further demonstrated the existence of both (i) strands with obviously homogeneous repeating units and (ii) strands with intra-axial heterogeneity of rDNA subunits. "Prelude complexes", i.e. groups of transcriptional complexes in apparent spacer intercepts, were not infrequently noted. The data are compared with the measurements of lengths of repeating units in fragments of rDNA obtained by digestion with EcoRI endonuclease as described by Morrow et al. (1974) and Wellauer et al. (1974, 1976a, b). The results are discussed in relation to problems of variations in the modes of arrangement of the pre-rRNA genes, the state of packing of rDNA during transcription, and possible mechanisms of the amplification process.
\end{abstract}

\section{Introduction}

In eukaryotic cells the DNA (rDNA) which contains the sequences coding for the cytoplasmic 18 and $28 \mathrm{~S}$ ribosomal RNAs (rRNAs) consists of numerous tandemly arranged "repeating units". Each repeating unit contains one sequence 
coding for the precursor molecule to the rRNAs (pre-rRNA), and an adjacent more or less extended sequence, which is not complementary to pre-rRNA (for references see Birnstiel et al., 1971; Wellauer and Dawid, 1974; Schibler et al., 1975; Spring et al., 1976). Miller and Beatty (1969) and Miller and Bakken (1972) have shown that this subdivision of the repeating unit can be directly visualized in the electron microscope after dispersion and spreading of the transcriptionally active nucleolar chromatin. Regions of transcription appear as "matrix units", i.e. axial intercepts densely covered by lateral ribonucleoprotein (RNP) fibrils arranged in a characteristic length gradient. Such matrix units containing nascent pre-rRNA are separated by usually fibril-free intercepts which are interpreted as nontranscribed "apparent spacer units" (for terminology see Franke et al., 1976a). In the clawed toad, Xenopus laevis, a detailed model of the arrangement of specific rDNA sequences in the repeating unit has been developed from work with isolated rDNA, rRNAs, and pre-rRNA (Dawid etal., 1970; Speirs and Birnstiel, 1974; Dawid and Wellauer, 1976; Schibler et al., 1976). In contrast to earlier concepts emphasizing the homogeneity of rDNA repeating units in Xenopus (e.g., Wensink and Brown, 1971; Brown et al., 1972; Forsheit et al., 1974), recent results obtained from cleavage patterns of rDNA with EcoRI restriction endonuclease have shown a striking size heterogeneity of repeating units which primarily reflects the heterogeneity of "spacer" lengths (e.g., Morrow et al., 1974; Wellauer et al., 1974, 1976a, b; Wellauer and Reeder, 1975). Heterogeneity of length of repeating units, including heterogeneity of apparent spacer units, has also been noted in the transcriptional units of spread nucleolar chromatin from diverse organisms such as certain green algae, insects, and amphibia (Miller and Beatty, 1969; Scheer et al., 1973; Spring et al., 1974, 1976; Trendelenburg et al., 1974, 1976, 1977; Berger and Schweiger, 1975; Foe et al., 1976). In order to answer the question whether the size heterogeneity of the repeating units observed in isolated Xenopus rDNA corresponds to the pattern observed in transcribed nucleolar chromatin we have undertaken a detailed quantitative study of the distribution and modes of arrangement of transcriptional units in the amplified rDNA of the Xenopus laevis oocytes. In addition, the electron microscopic examination of spread nucleolar chromatin allows an analysis of the size and arrangement of rDNA repeating units in individual strands.

\section{Material and Methods}

1. Animals. African clawed toads (Xenopus laevis) were kept in large water tanks at $20-22^{\circ} \mathrm{C}$ under a $12 \mathrm{~h}$ light-dark rhythm. Some animals were induced to ovulate by the injection of 500 IU of a human chorion gonadotropic hormone (Predalon; Fa. Organon, Munich). Animals heterozygous for the anucleolate mutation (1-nu; cf. Elsdale et al., 1958) were kindly provided by Dr. M. Fischberg (Université de Genève, Switzerland).

2. Electron Microscopy and Morphometric Determinations. Nuclei from lampbrush chromosome-stage oocytes (diameter ca. $500 \mu \mathrm{m}$ ) were manually isolated in a $\mathrm{NaCl}$ and $\mathrm{KCl}$ containing medium buffered with $10 \mathrm{mM}$ Tris- $\mathrm{HCl}$ to $\mathrm{pH} 7.2$ (Scheer et al., 1973). To separate the extrachromosomal, peripheral nucleoli from chromosomal material a nucleus was punctured with 2 fine needles, and the nuclear envelope, together with the tightly adhering nucleoli, was removed by aspiration into 
a micropipette and transferred into a drop of the spreading solution. For each preparation nucleolar material obtained from a single oocyte was used. The spreading solutions were either (i) $0.1-0.5 \mathrm{mM}$ borate buffer, pH 9 (" pH 9-water"; Miller and Bakken, 1972), or (ii) pH 9-water with 0.05-0.1\% of the anionic detergent Sarkosyl NL-30 (Ciba-Geigy, Basel, Switzerland; cf. Franke et al., 1976b), or (iii) $\mathrm{pH}$ 9-water with $0.01 \%$ of the detergent 'Joy' (Miller and Bakken, 1972), or (iv) $\mathrm{pH}$ 9-water containing $100 \mu \mathrm{g} / \mathrm{ml}$ tRNA (isolated from E. coli) with or without Sarkosyl (see also Foe et al., 1976). The nucleolar material was allowed to disperse for 10 to $20 \mathrm{~min}$ at about $10^{\circ} \mathrm{C}$ and was then centrifuged as previously described (Scheer et al., 1973). Material applied to electron microscopic grids was then positively stained (Miller and Bakken, 1972). Some preparations were additionally metal shadowed with platinum-palladium $(80: 20)$ at an angle of $7^{\circ}$. Micrographs were taken with a Zeiss EM-10 electron microscope at $60 \mathrm{kV}$. The magnification was determined from micrographs of grating replicas.

Calibrated positive prints were projected onto a digitizer tablett. Calculations and distribution analysis were made with the use of a computer program kindly developed by R. Zentgraf, Dipl. Math. (Institute of Documentation and Statistics, this center). Matrix units, apparent spacer units, and repeating units were measured as described previously (Trendelenburg et al., 1976; cf. also Scheer et al., 1976a).

3. Gel Electrophoresis of RNA. Lampbrush chromosome stage oocytes were isolated from females which had been induced to ovulate one day before and were incubated in Eagle's minimal essential medium (1:1 v/v diluted with distilled water) containing all four tritiated ribonucleosides (for further details see Scheer et al., 1975) at $23^{\circ} \mathrm{C}$ for $17 \mathrm{~h}$. RNA was extracted from isolated nuclei as described previously (Scheer, 1973; Scheer et al., 1973). After the addition of E. coli rRNAs (mol. wts. 0.525 and $1.05 \times 10^{6}$, cf. Fellner et al., 1974; Spohr et al., 1976) and tobacco mosaic virus RNA (TMV-RNA, assumed mol. wt. $2.07 \times 10^{6}$, cf. Reijnders et al., 1974) the total RNA was precipitated with $2.5 \mathrm{vol}$ absolute ethanol. The samples were analyzed either under nondenaturing conditions in cylindrical $2.4 \%$ acrylamide gels (Loening, 1969) or under fully denaturing conditions in exponential 3-7\% acrylamide gels containing formamide at $50^{\circ} \mathrm{C}$ (Spohr et al., 1976). Gels were scanned at $260 \mathrm{~nm}$ in order to determine the position of the marker RNAs, then frozen on solid dry ice, cut into $1 \mathrm{~mm}$ thick slices, and the radioactivity was determined (cf. Scheer et al., 1973; Spring et al., 1976).

\section{Results}

In general, the nucleolar chromatin from oocytes of Xenopus laevis is less readily dispersed and spread than that from oocytes of various urodelan species (the literature presents relatively few micrographs; cf. Miller and Beatty, 1969; Schibler et al., 1976; Reeder et al., 1976). When amplified nucleoli from lampbrush stage oocytes of $X$. laevis were spread under standard conditions (" $\mathrm{pH} 9$-water", see Methods) mostly dense aggregates of nucleolar chromatin strands were observed. These nucleolar aggregates were deposited as distinct isolated units and each seemed to be composed of several hundred matrix units. Even after prolonged dispersion of the nucleoli in very low salt concentrations (up to 40 min incubation), only an average of one out of eight preparations allowed a sufficiently precise length determination of transcribed and apparently untranscribed units of chromatin strands, and this was mostly limited to axes in the periphery of the nucleolar aggregates (e.g., Fig. 1). A typical aspect of well spread tandemly arranged pre-rRNA genes of $X$. laevis oocytes, as observed after dispersion in " $\mathrm{pH} 9$-water", centrifugation and positive staining, 


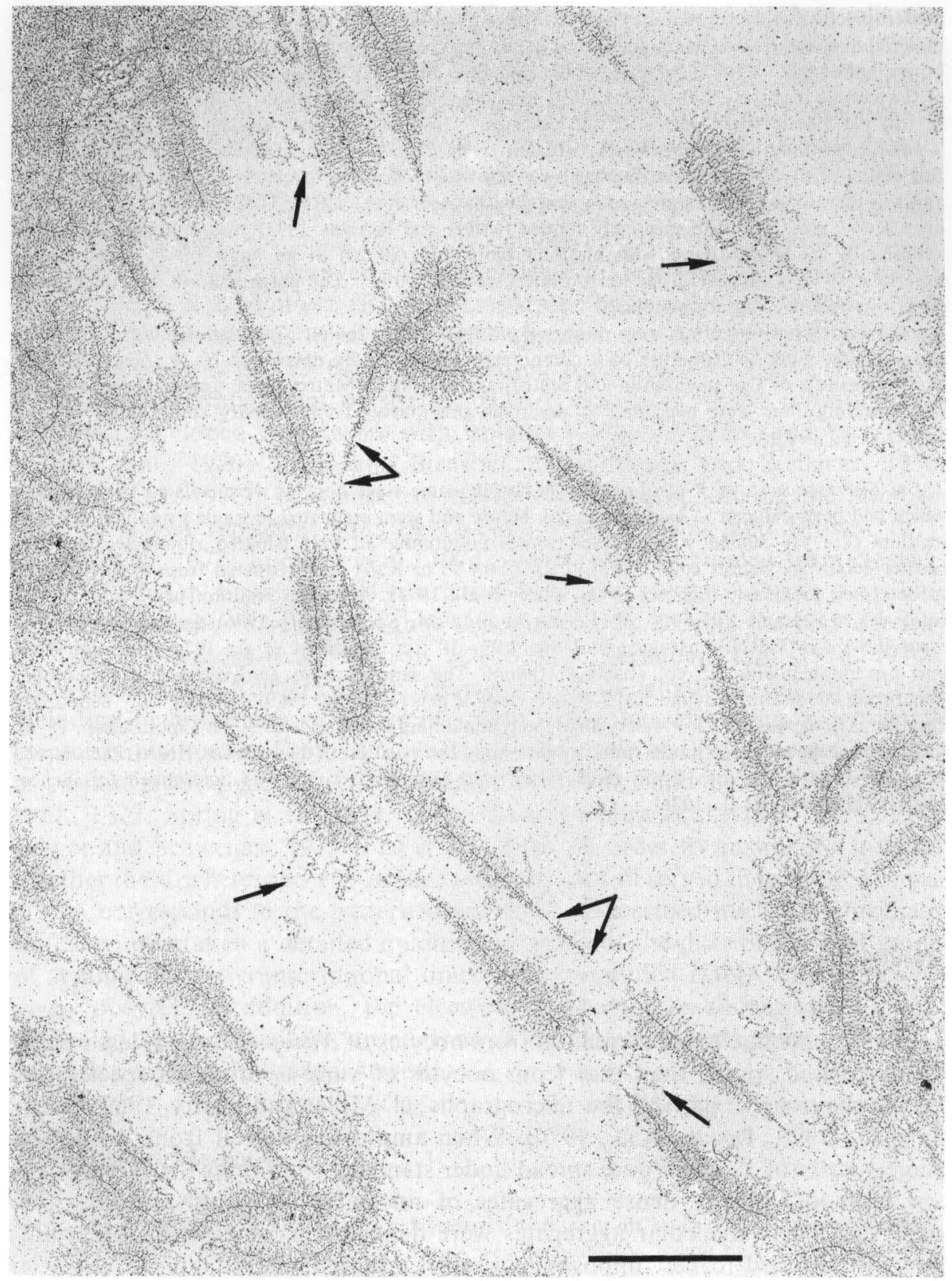

Fig. 1. Survey electron micrograph of spread nucleolar material isolated from an oocyte of Xenopus laevis (1-nu mutant). The material was dispersed and positively stained with phosphotungstic acid (see Materials and Methods). Strands of transcribed nucleolar chromatin show the typical pattern of tandemly arranged matrix-covered regions separated by fibril-free intercepts (apparent spacer regions). Occasionally, individual groups of lateral fibrils are seen close to the beginning of a matrix unit in apparent spacer regions ("prelude complexes"; double arrows). Single "isolated" fibrils that might represent detached matrix fibrils are also present in this preparation, often in close association with the matrix units (arrows; note the tendency of this fibrillogranular material to aggregate into complex structures). Bar represents $2 \mu \mathrm{m}$ 


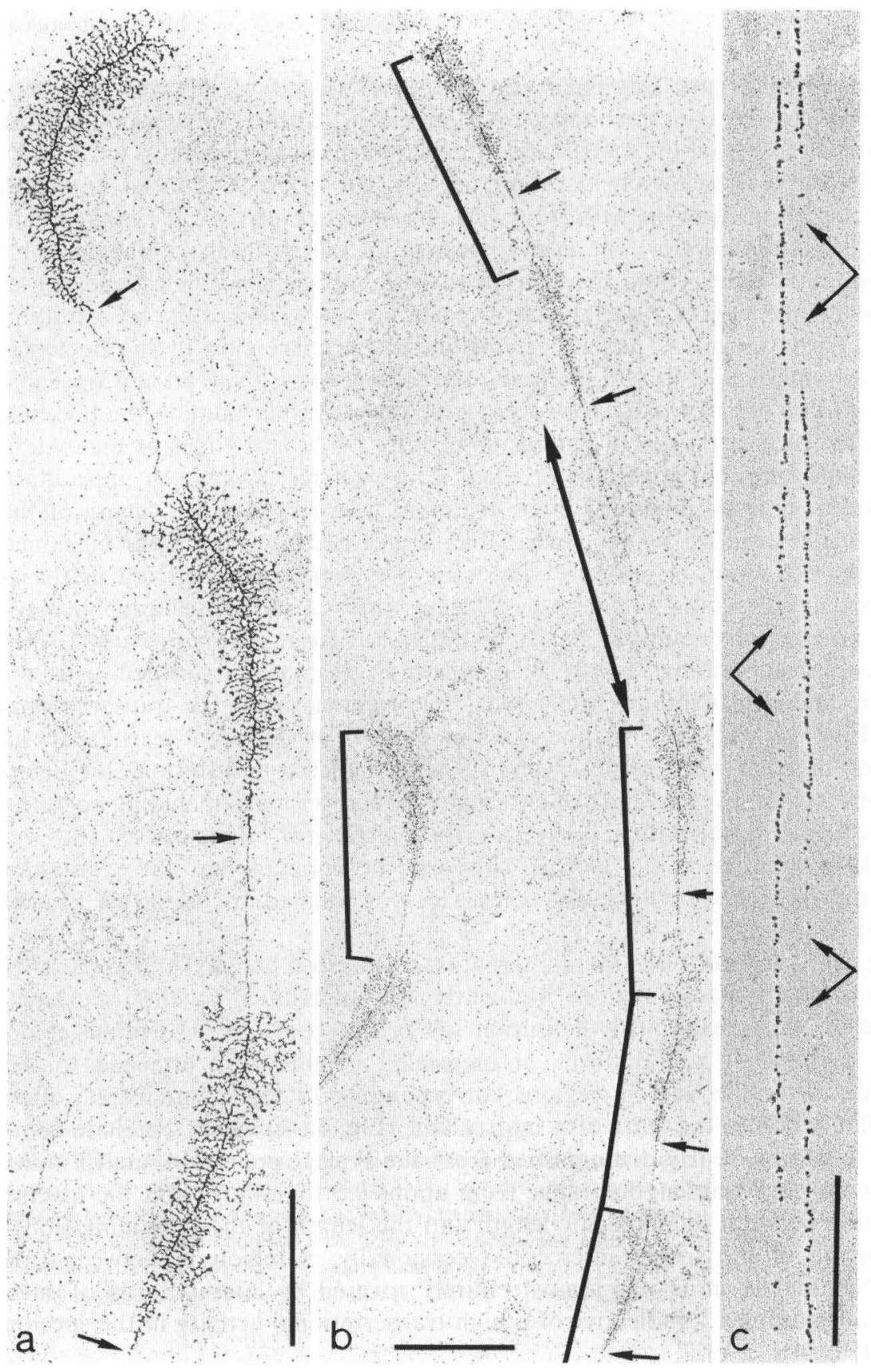

Fig. 2a-c. Strands of transcriptionally active nucleolar chromatin dispersed without detergent (a) and with $0.01 \%$ "Joy" (b) or $0.05 \%$ Sarkosyl NL-30 (c); for details of preparation see Material and Methods). In the preparation shown in $\mathbf{c}$ most of the material of the lateral fibrils has been removed from the RNA polymerase granules (see text). Note that in all three different preparations the apparent spacer axes are free of distinct and regularly spaced particles and that they appear much thinner in Sarkosyl-treated chromatin (double arrows in $\mathbf{c}$; this preparation has been metal shadowed). The arrows in $\mathbf{a}$ and $\mathbf{b}$ point to the start regions of the specific matrix units, repeating units are denoted by brackets (b). One extraordinarily long matrix-free intercept is indicated in b by the double-headed arrow. Such extremely long units have not been considered as identified spacer regions in our quantitative evaluations since they might as well reflect the inclusion of one non-transcribed pre-rRNA gene. Bars represent $1 \mu \mathrm{m}(\mathbf{a}, \mathbf{c})$ and $2 \mu \mathrm{m}(\mathbf{b})$ 
is presented in Figure 2 a. Each matrix unit consisted of an axial intercept to which 80 to 100 lateral ribonucleoprotein (RNP) fibrils of increasing lengths were attached. Within the matrix units the increment of fibril lengths (cf. Franke et al., 1976a) was relatively constant, in contrast to the situations found in similar preparations of nucleoli from various other organisms (cf. Franke et al., 1976a; Laird et al., 1976). The axial lengths of the matrix units, i.e. the apparent transcriptional units, could be determined with sufficient accuracy, and consequently also the lengths of the apparent spacer intercepts (e.g., Fig. 2a). Addition of low concentrations of detergents facilitated the dispersion of the nucleolar chromatin and resulted in an increased proportion of well spread and traceable axes (e.g., Figs. 2b, 6a-c, 8). However, some preparations made in the presence of elevated concentrations of detergents or after prolonged times of incubation in low detergent concentrations revealed an aspect resembling the appearance of nucleolar chromatin spread after treatment with ribonuclease: many of the lateral fibrils were no longer identifiable, either because they were unstained due to the extraction of proteins or because they were removed from the basal RNA polymerase-containing granules ${ }^{1}$. Nevertheless, even in such preparations, matrix unit regions could be clearly distinguished from spacer intercepts since the granules containing the RNA polymerase remained associated with the template and thus exhibited the typical arrangement of active transcriptional units (Figs. 2c and 3). This non-random pattern of detergent-resistant basal granules, together with the observation that at higher concentrations the detergent Sarkosyl removes the bulk of chromatin-bound proteins, including histones, but leaves the transcriptional complex proper intact (for references see Gariglio et al., 1974; Franke et al., 1976b), supports the concept that these granules indeed represent RNA polymerase complexes (for detailed discussion see Franke et al., 1976b).

The characteristic sequence of alternating transcribed (matrix) and apparently non-transcribed (spacer) regions frequently was interrupted by the occurrence of "prelude complexes" (for definition see Scheer et al., 1973; Franke et al., $1976 \mathrm{a})$. Groups of lateral fibrils of increasing lengths were attached to the nucleolar chromatin axes in regions corresponding to spacer intercepts, often immediately before the start of a matrix unit (Fig. 4a-e). Such "prelude complexes" could be clearly distinguished from the typical pre-rRNA matrix units by their shorter axial lengths (range from about 0.5 to $1.4 \mu \mathrm{m}$ ) and the inverse correlation between their specific length and the length of the remaining fibrilfree portion of the spacer intercept. Occasionally, a region in between two pre-rRNA matrix units was almost entirely covered by lateral fibrils of such a "prelude complex", indicative of a high transcriptional activity in the specific spacer (Fig. 4 b, c, e).

\footnotetext{
${ }^{1}$ The extent to which these detergents, even at the highest concentrations used, resulted in such a disappearance or "invisibility" of the lateral fibrils was quite variable. We do not know, whether this effect is due to either the partial or complete removal of proteins attached to the nascent pre-rRNA, which then would make the RNA unstainable and/or more accessible to endogenous nucleases, or to an activation of nucleases by the detergents. Addition of transfer RNA to the detergent-containing spreading solution in order to reduce the action of nucleases did not result in the reproducible maintenance of visible lateral fibrils
} 


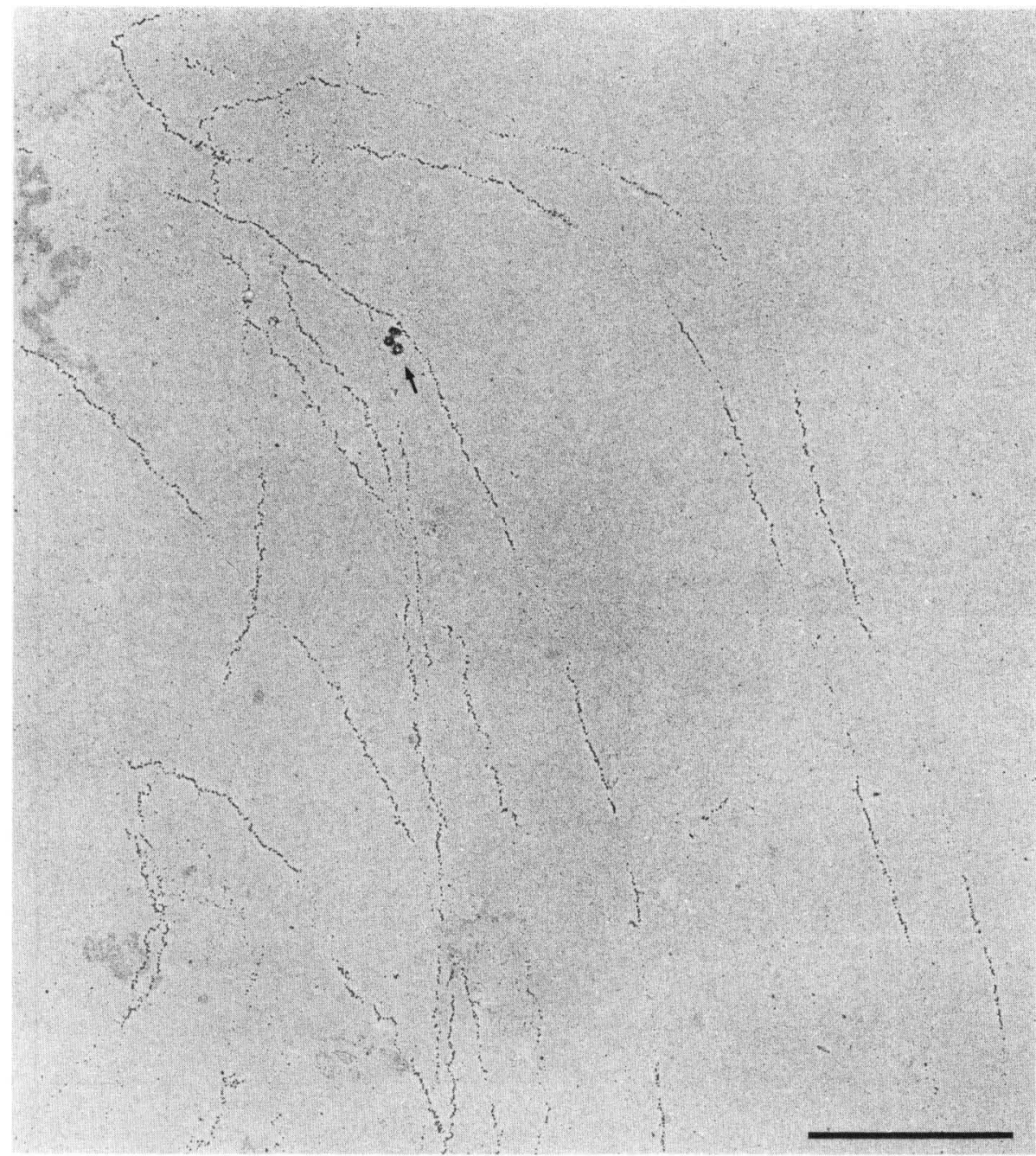

Fig. 3. Survey electron micrograph showing the appearance of nucleolar chromatin dispersed and spread in the presence of $0.05 \%$ Sarkosyl as revealed after positive staining and metal shadow cast (cf. also Fig. 2c). Although the matrix material has been removed from the axes the clusters of RNA polymerase-containing particles still display the pattern of transcribed and apparently non-transcribed regions along the rDNA-containing strands. The arrow denotes a nuclear envelope fragment of three isolated pore complexes. The bar represents $2 \mu \mathrm{m}$

Length distributions of matrix units, spacer regions and repeating units were determined in different oocytes from different animals of normal (2-nu) or mutant (1-nu) nucleolus organizer constitution (selected histograms from three different animals are presented in Fig. 5a-c). Apparent spacer units were measured as the distance between two adjacent pre-rRNA containing matrix units (for definition of "matrix unit" see Trendelenburg et al., 1976), irrespective of the occurrence of transcriptional activities such as in "prelude complexes" 

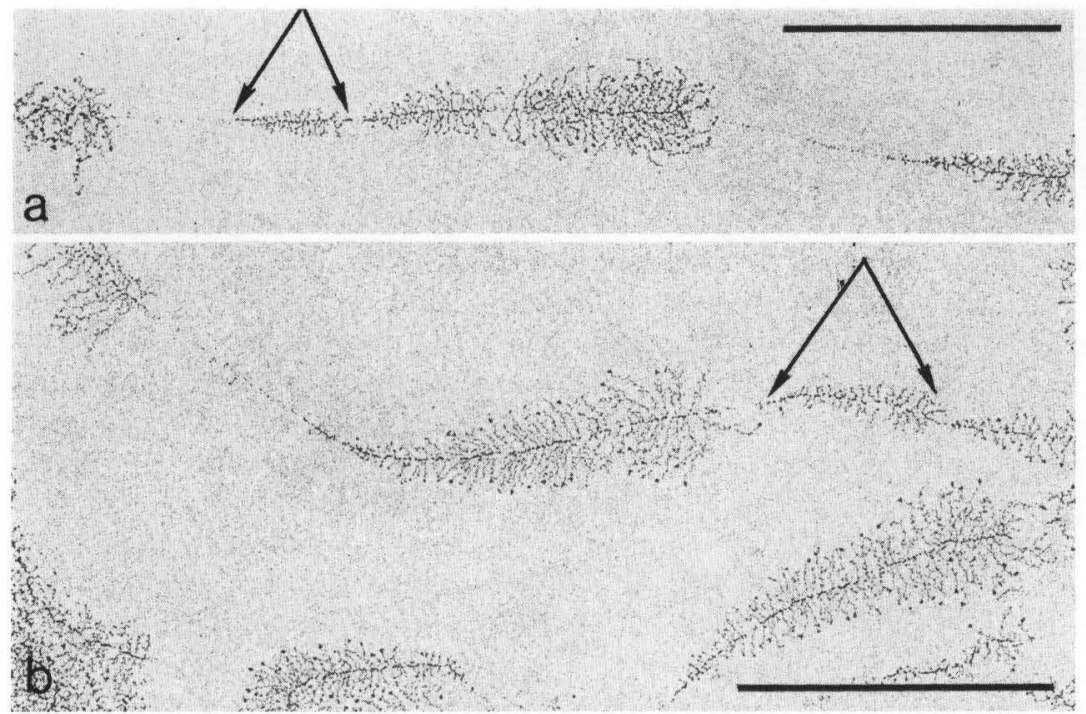

C
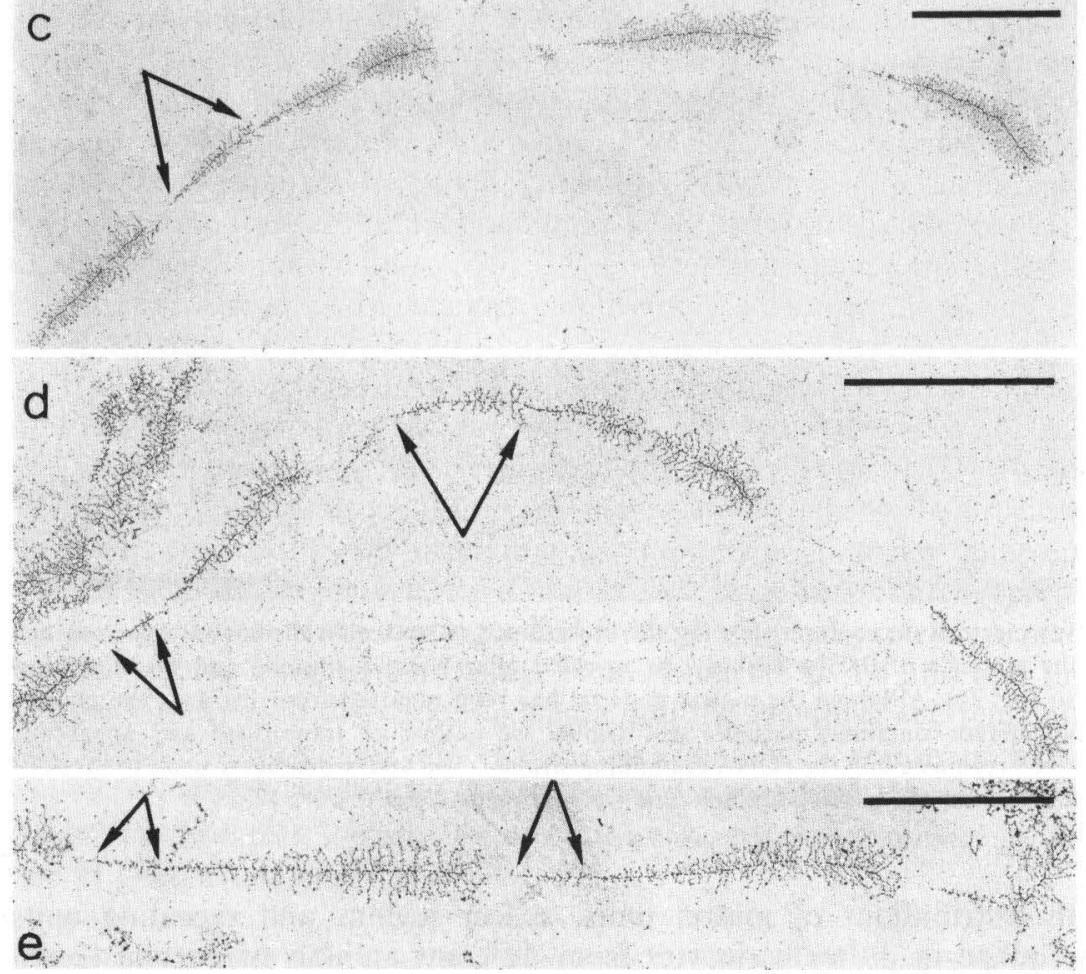

Fig. 4a-e. Examples of transcriptional complexes in nucleolar chromatin that are attached to apparent spacer regions in the form of "prelude complexes" (double arrows). A variable proportion of the spacer sections (in some cases up to $80 \%$, cf. b) are covered by ribonucleoprotein fibrils arranged in characteristic length gradients with the same polarity as that of the adjacent matrix units. The terminal fibril of a prelude piece and the first small fibril of the adjacent matrix unit are sometimes separated by another short intercept of apparently non-transcribed spacer (e.g. b, c). Bars represent $2 \mu \mathrm{m}$ 


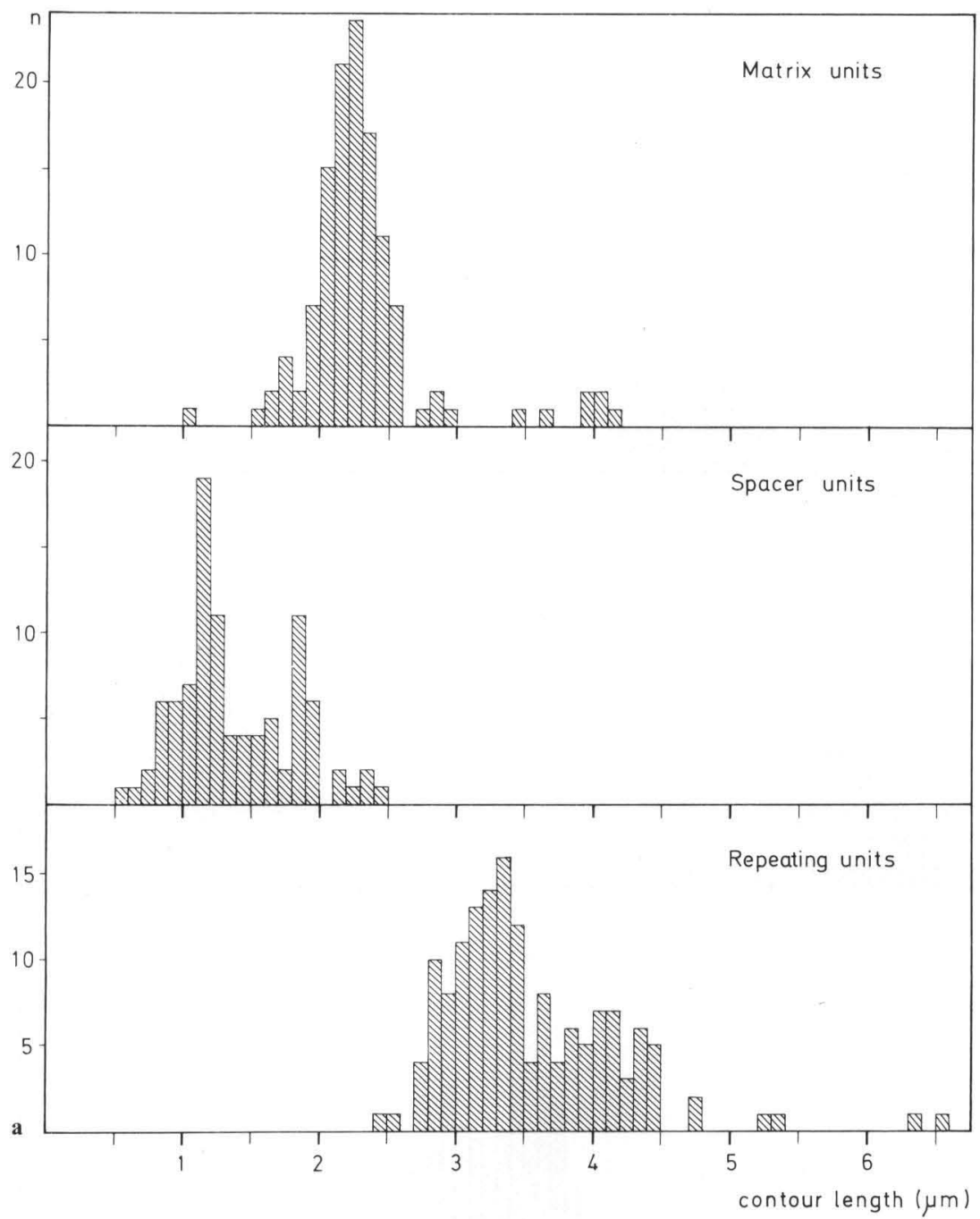

Fig. 5a-c. Histograms of the size frequencies of matrix units, apparent spacer units, and the resulting repeating units in spread nucleolar chromatin from three different toads. Oocyte nuclei were isolated from two wild-type animals, and the nucleoli were dispersed without (a) or with detergents (b). Alternatively, oocyte nuclei from a 1-nu mutant were dispersed and spread in the presence of detergents (c). Heterogeneity of lengths is noted, with some indications of the existence of subclasses. The heterogeneities of the repeating units appear to reflect the positive skew of the distribution of the matrix unit and spacer unit sizes. This also shows that matrix units of greater lengths do not correspond to adjacent short spacer units or vice versa. In such skewed distributions the mean is not meaningful, whereas the use of the median makes sense. In addition, the standard deviation $\sigma$ is replaced here by the "sextile difference", i.e. the difference between the percentiles 84 and 16 . This term means that $68 \%$ of all values are within this range of deviation. The specific median values, confidence intervals (level of significance $\alpha=0.05$ ), and deviations ("sextile differences") are as follows (all values in micrometers): a Matrix units: 2.22, 2.17-2.26, 2.0-2.42; spacer units: $1.24,1.17-1.37,0.98-1.83$; repeating units: $3.34,3.25-3.41,2.95-4.10$. b Matrix units: 2.59 , $2.56-2.63,2.33-2.95$; spacer units: $1.27,1.25-1.34,1.10-1.70$; repeating units: $3.87,3.82-3.95$, 3.51-4.42. c Matrix units: $2.38,2.32-2.40 .2 .17-2.63$; spacer units : $0.97,0.95-1.0,0.81-1.18$; repeating units: $3.36,3.31-3.40,3.10-3.88$ 


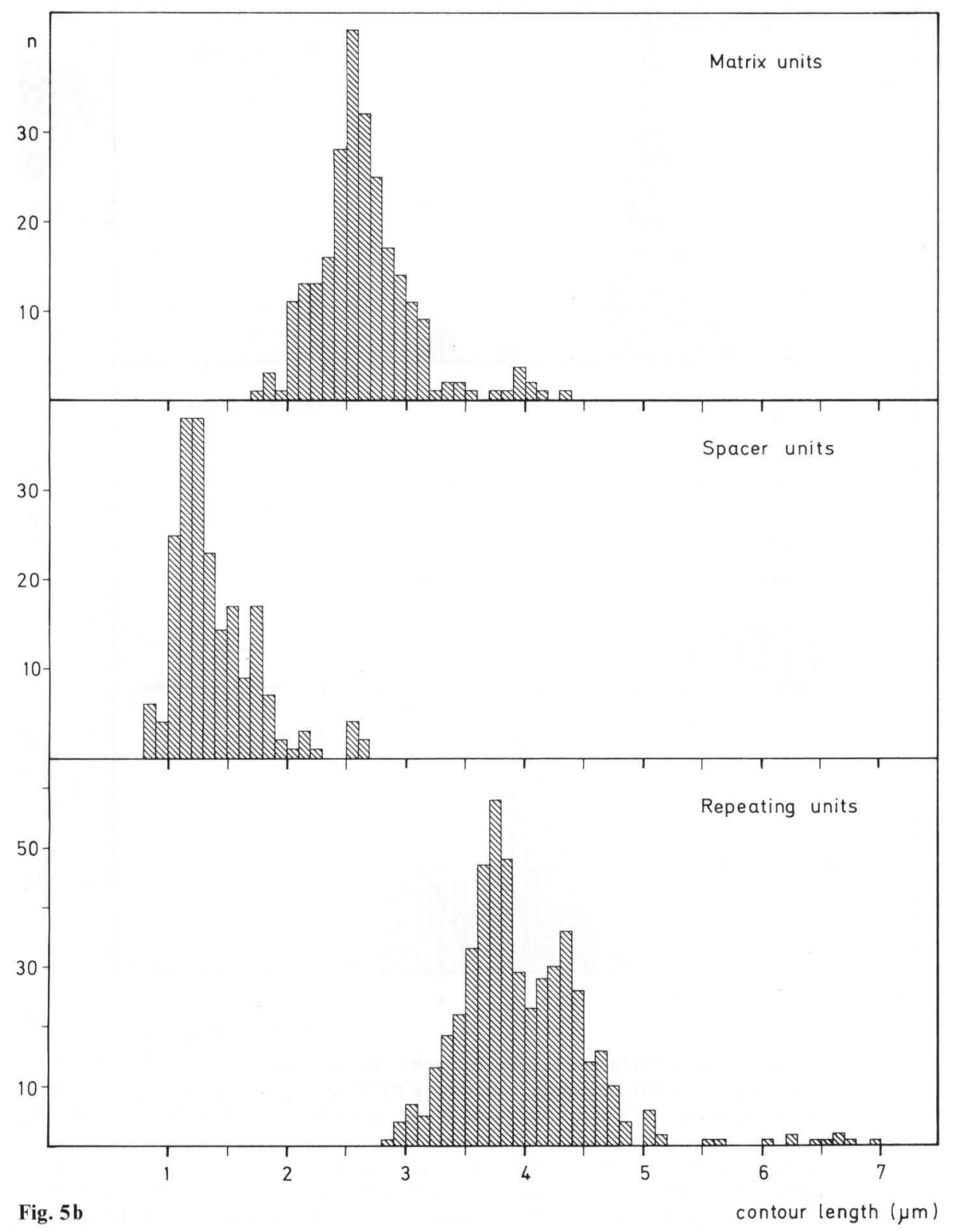

(see above) in the specific spacer intercept. Addition of detergents did not result in significant changes of the lengths of these chromatin units (comp. Fig. 5a with Fig. 5b and c). Median values for matrix unit lengths were consistently in the range from 2.2 to $2.6 \mu \mathrm{m}$. However, in all spread preparations examined, matrix units with lengths from 3.4 to $4.2 \mu \mathrm{m}$ were also found (e.g., Figs. $7 \mathrm{~b}, \mathrm{c}$ and 8 ), this resulting in distribution curves skewed to the right. Spacer intercepts had lengths ranging from 0.5 to $2.5 \mu \mathrm{m}$, with size frequencies 


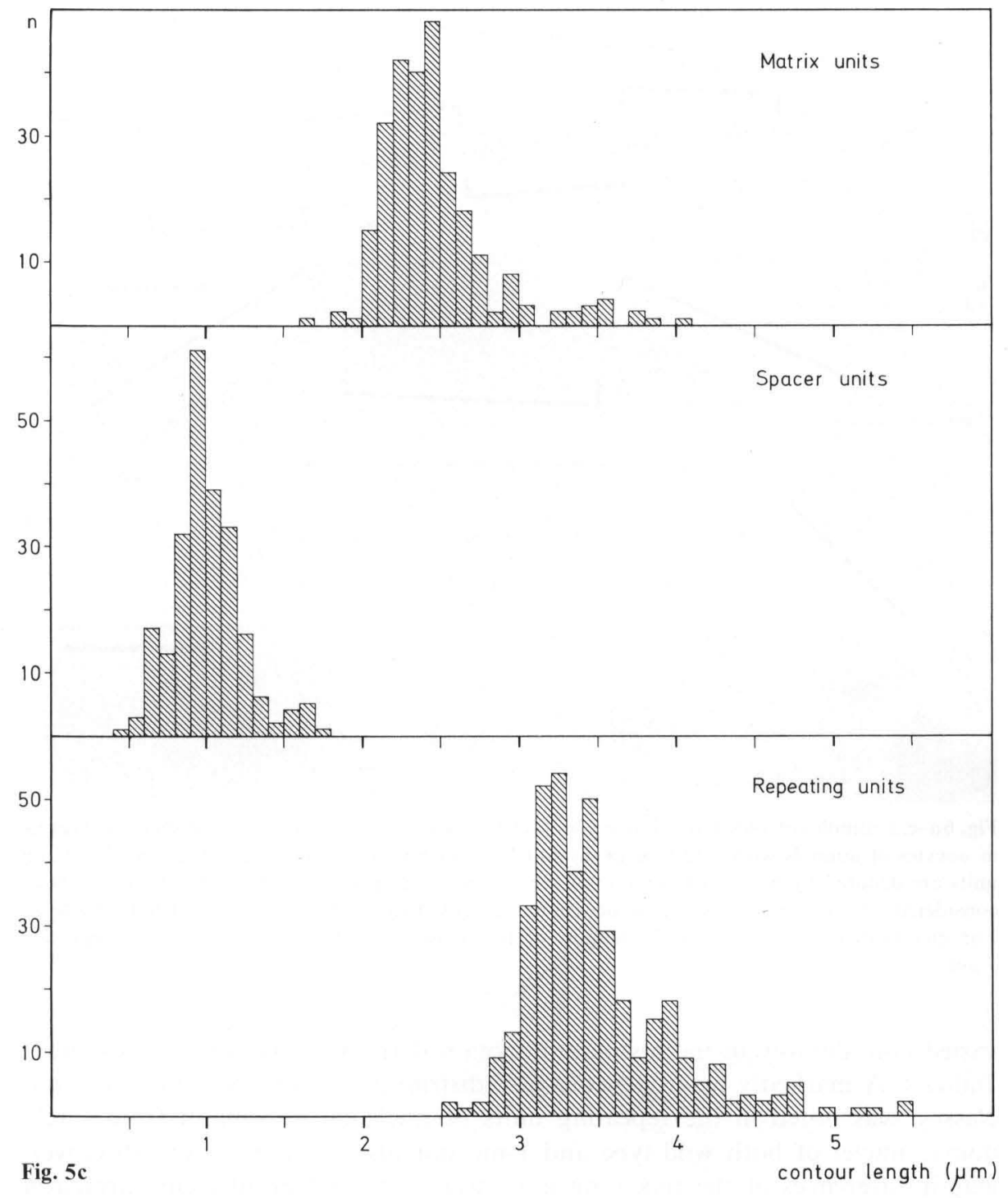

mostly distributed in a non-Gaussian mode. In some oocytes, two discrete size classes of the spacer could be recognized (e.g., Fig. 5a). Occasionally occurring extremely long apparent spacer units (4.5 to $6.5 \mu \mathrm{m}$; e.g., Fig. 2 b) were not considered in these histograms since it cannot be excluded that these regions include transcriptionally inactive pre-rRNA genes (for examples of inactivated nucleolar chromatin see Scheer et al., 1973, 1975, 1976 b; McKnight and Miller, 1976). Repeating units showed a broad distribution of their lengths, ranging from 2.4 to $7 \mu \mathrm{m}$, and the histograms obtained usually indicated the existence of discrete subclasses (predominant size classes, for example, were $3.2-3.4 \mu \mathrm{m}$, $3.7-3.8 \mu \mathrm{m}, 4.3-4.4 \mu \mathrm{m}, 4.6-4.8 \mu \mathrm{m})$. The relative proportions of the size classes 


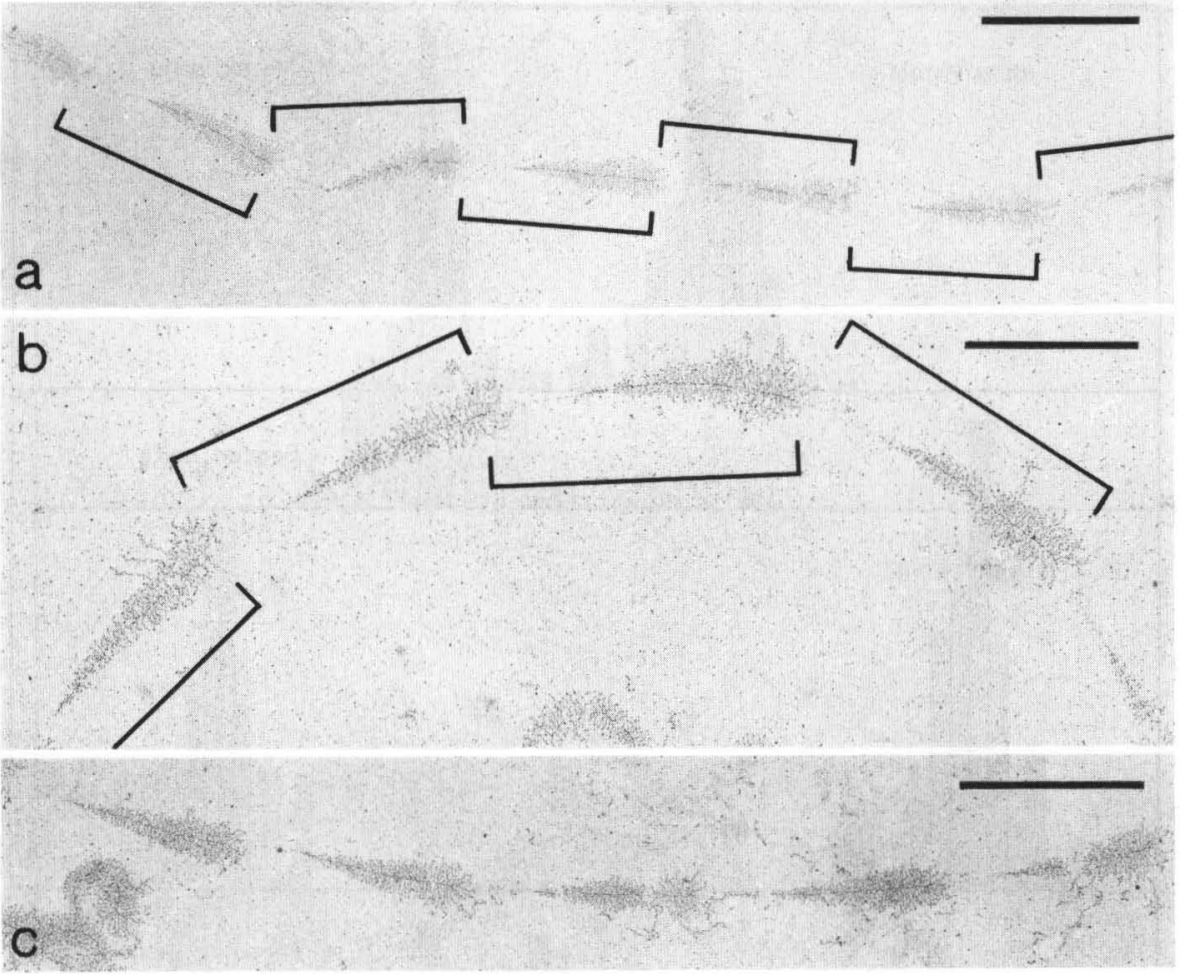

Fig. 6a-c. Examples of axes with relatively homogeneous arrays of matrix units and spacer intercepts in oocytes of animals with wild-type (a, b) and 1-nu (c) genetic nucleolar constitution. Repeating units are denoted by brackets (only one of the two possible spacer-matrix combinations has been considered). Some matrix units show occasional irregularities in the lateral fibril length gradient. For quantitative evaluations of the lengths of the repeating units see Fig. $9 \mathrm{a}-\mathrm{c}$. Bars represent $3 \mu \mathrm{m}$

varied considerably in the histograms obtained from preparations of different animals. A markedly heterogeneous size distribution, with indications of subclasses, was noted in the repeating units of nucleolar chromatin from single oocyte nuclei of both wild-type and 1-nu animals (see Fig. 5a-c). Moreover, length differences of the repeating units were observed in adjacent chromatin strands which were presumably derived from the same nucleolus (e.g., Fig. 7 a-c). It should be emphasized that the length variability of the repeating units could reflect variations of both the apparent spacer region and/or the matrix unit.

When individual chromatin strands were evaluated, both the matrix units and the spacer units of a specific strand were mostly of similar length ("strands with a homogeneous pattern"; e.g., Figs. 6a-c, 9a-c). However, we repeatedly also observed nucleolar strands with different lengths of both matrix units and spacer units (e.g., Figs. $7 \mathrm{~d}, 8$, and $9 \mathrm{~d}$, e). In some strands, groups of repeating units of identical size could be found adjacent to repeating units of a different size class, which may suggest a tendency to clustering of identical repeating units (Fig. 8). Size variability of matrix units, spacer units, and the 


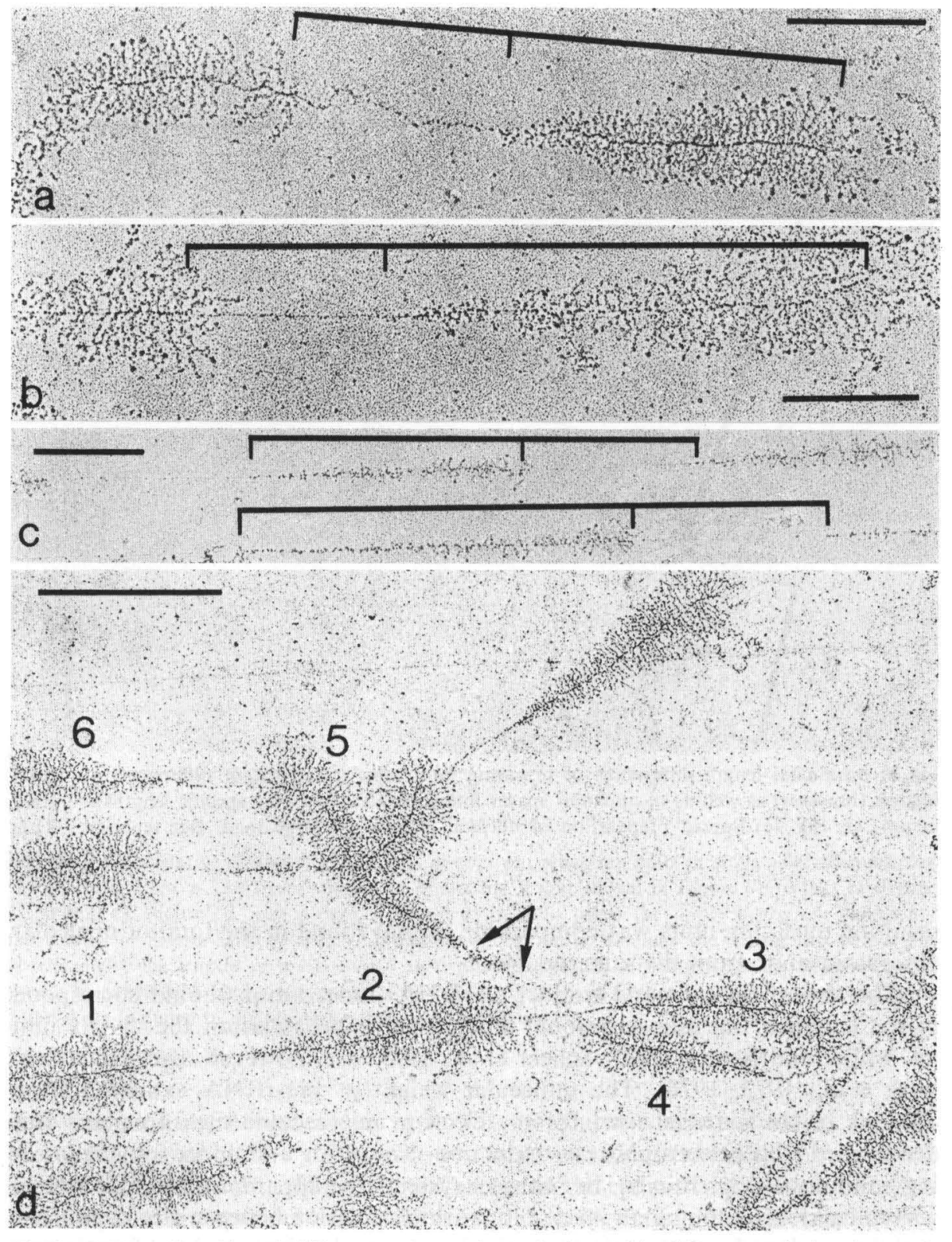

Fig. 7a-d. Examples of length differences of repeating units located in different nucleolar chromatin strands (inter-axial heterogeneity, a-c) and on a continuous axis (intra-axial heterogeneity, d). Repeating units (indicated by brackets in a-c) with lengths of $4.2 \mu \mathrm{m}$ (matrix unit $2.5 \mu \mathrm{m}+$ spacer unit $1.7 \mu \mathrm{m}$; a) and $5.0 \mu \mathrm{m}(3.5+1.5 \mu \mathrm{m}$; b) in a nucleolar core of a toad with wild-type (2-nu) genetical constitution are compared in $\mathbf{a}$ and $\mathbf{b}$; $\mathbf{c}$ presents the direct comparison of repeating units with 4.0 and $5.2 \mu \mathrm{m}$ in adjacent strands (in this preparation a treatment with Sarkosyl has resulted in somewhat decreased staining and/or preservation of the lateral fibril material). Matrix units in $\mathbf{d}$ are numbered in sequence, a "prelude complex" is indicated by the double arrow. Note the relatively small size of matrix unit No. 4 and its preceding spacer (for quantitative evaluation see Fig. 9d). Bars represent $1 \mu \mathrm{m}(\mathbf{a}-\mathbf{c})$ and $2 \mu \mathrm{m}(\mathbf{d})$ 


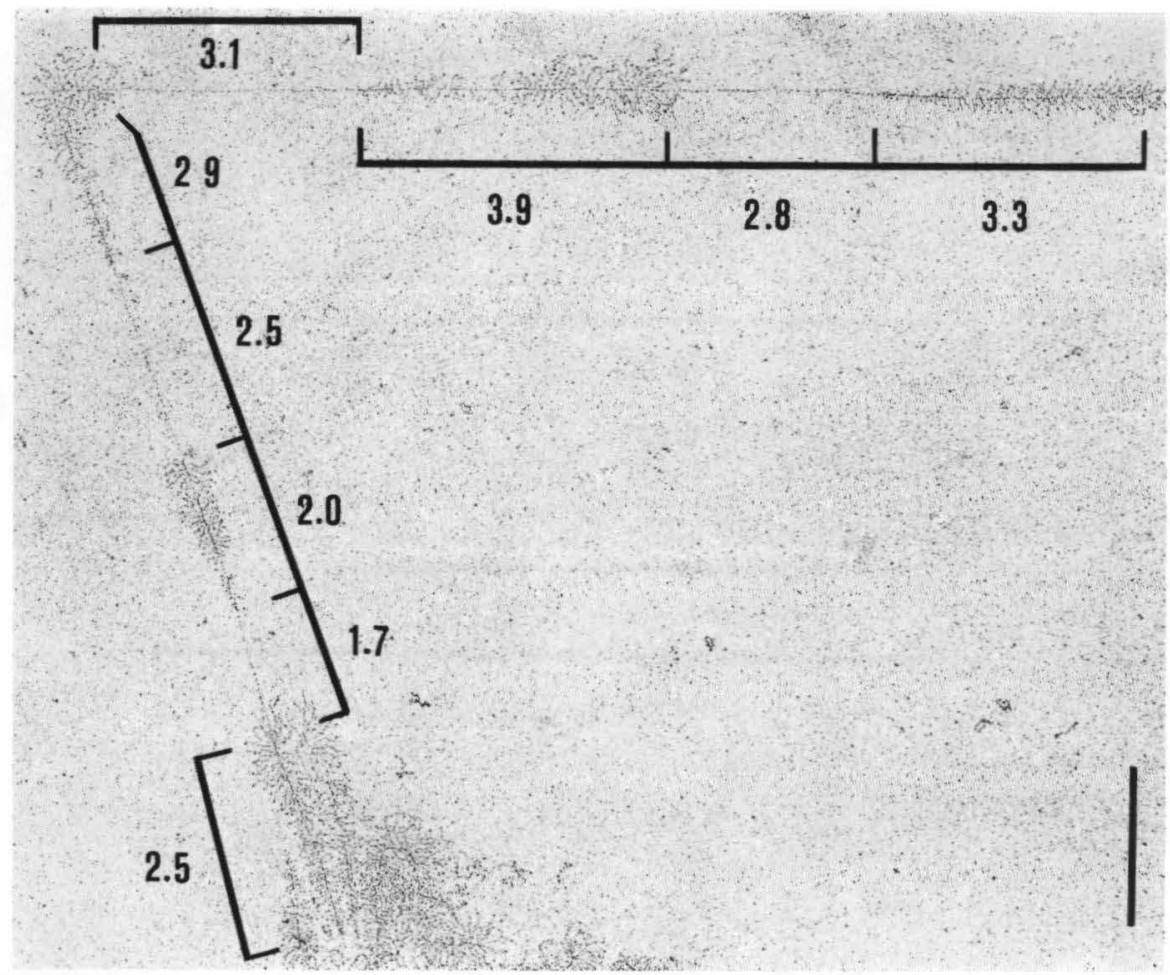

Fig. 8. Intra-axial length differences of repeating units may reflect length differences of matrix regions (brackets) as well as of apparent spacer intercepts (brackets; the specific lengths are given in $\mu \mathrm{m}$; cf. Fig. 9e) Spread preparation of nucleoli from a wild-type toad. Bar represents $2 \mu \mathrm{m}$

resulting repeating units was comparable to that found in the total of nucleolar chromatin units from the same oocyte.

The size of the primary product of rDNA transcription should correspond to the length of the transcriptional unit, i.e. in approximation the matrix unit (cf. Miller and Beatty, 1969; Scheer et al., 1973; see, however, also Trendelenburg et al., 1973, 1976). The molecular weight of pre-rRNA extracted from aliquots of the material used for the electron microscopic measurements was determined by gel electrophoresis under non-denaturing and under fully denaturing conditions (Fig. 10a, b). In both gel systems the apparent molecular weight was calculated, assuming an inverse logarithmic relation between electrophoretic mobility and molecule length, from the known molecular weights of coelectrophoresed reference RNAs. When analyzed on a non-denaturing $2.4 \%$ polyacrylamide gel, the pre-rRNA from Xenopus laevis oocytes appeared as a symmetrical peak with an apparent molecular weight of $2.55 \times 10^{6}$ (Fig. 10a), in agreement with values obtained with similar gel systems (e.g., Loening et al., 1969; Rogers and Klein, 1972; Bird et al., 1973; Scheer, 1973; Hagenbüchle et al., 1975) as well as with estimates from electron microscopic measurements of spread RNA molecules (Wellauer and Dawid, 1974; Schibler et al., 1975). Under dena- 


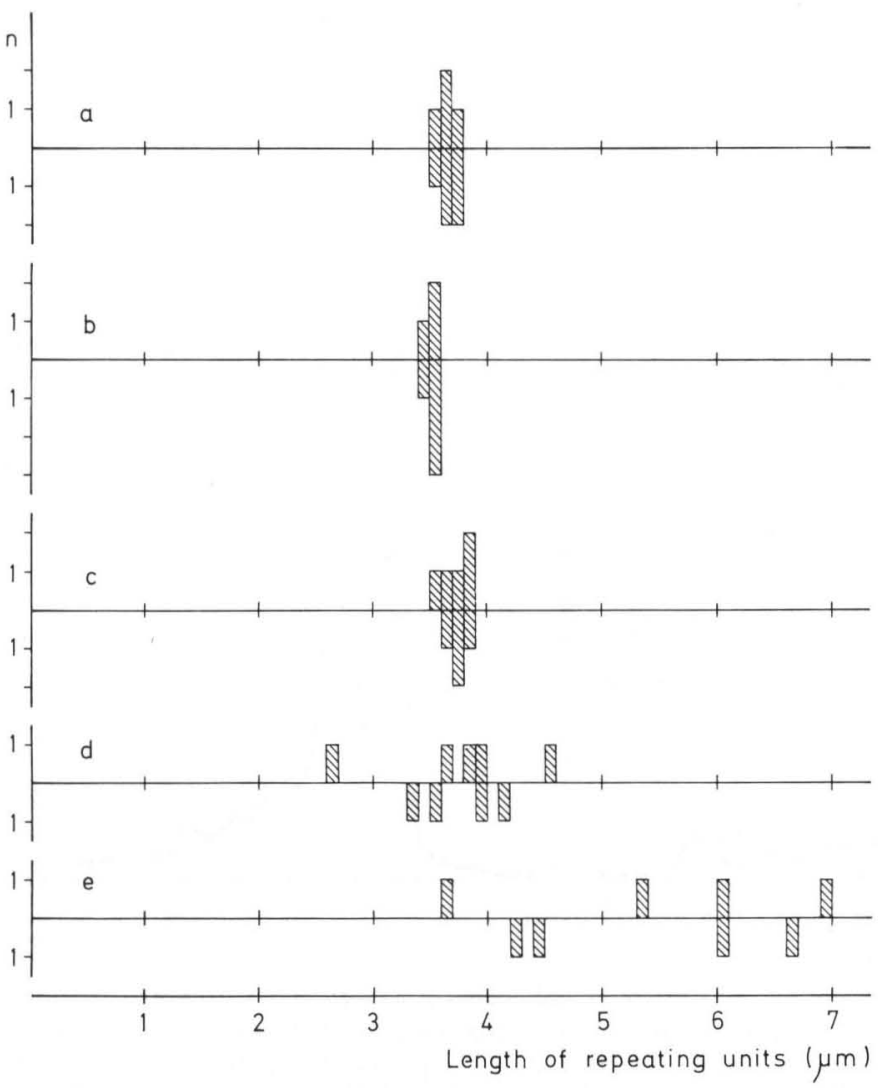

Fig. 9a-e. Quantitative evaluation of lengths of adjacent repeating units in some selected nucleolar chromatin strands. a The strand shown in Figure $6 \mathbf{a}, \mathbf{b}$ that shown in Figure $6 \mathrm{~b}$, $\mathbf{c}$ that of Figure $6 \mathrm{c}$, $\mathbf{d}$ that of Figure $7 \mathrm{~d}$, and $\mathbf{e}$ that of Figure 8 . In each panel the upper histogram represents the lengths of matrix units plus their preceding spacer units, whereas the histograms below the abscissae give the lengths of these matrix units plus the specific subsequent spacer. Measurements shown in panels a, b, and $\mathbf{e}$ are included in the distribution of Figure $5 \mathrm{~d}$, those shown in panels $\mathbf{c}$ and $\mathbf{d}$ are included in the histogram presented in Figure $5 \mathrm{~b}$

turing conditions, however, the apparent molecular weight estimated for the pre-rRNA was only $2.1 \times 10^{6}$ and showed an almost identical mobility to tobacco mosaic virus RNA (Fig. 10b). The difference in the estimated molecular weights was not due to a partial degradation of the RNA during the electrophoresis. This could be excluded by experiments in which the pre-rRNA was eluted from the peak obtained after electrophoresis under denaturing conditions and then re-electrophoresed under non-denaturing conditions in which the apparent molecular weight again was 2.5 to $2.6 \times 10^{6}$. Correspondingly lower apparent molecular weights were also estimated for the mature 28S rRNA but not for 18S rRNA frøm Xenopus laevis ovaries (molecular weights of 1.45 and $0.63 \times 10^{6}$ under non-denaturing conditions, and 1.30 and $0.63 \times 10^{6}$ under denaturing conditions). A final estimate of the true size of the pre-rRNA cannot be made 


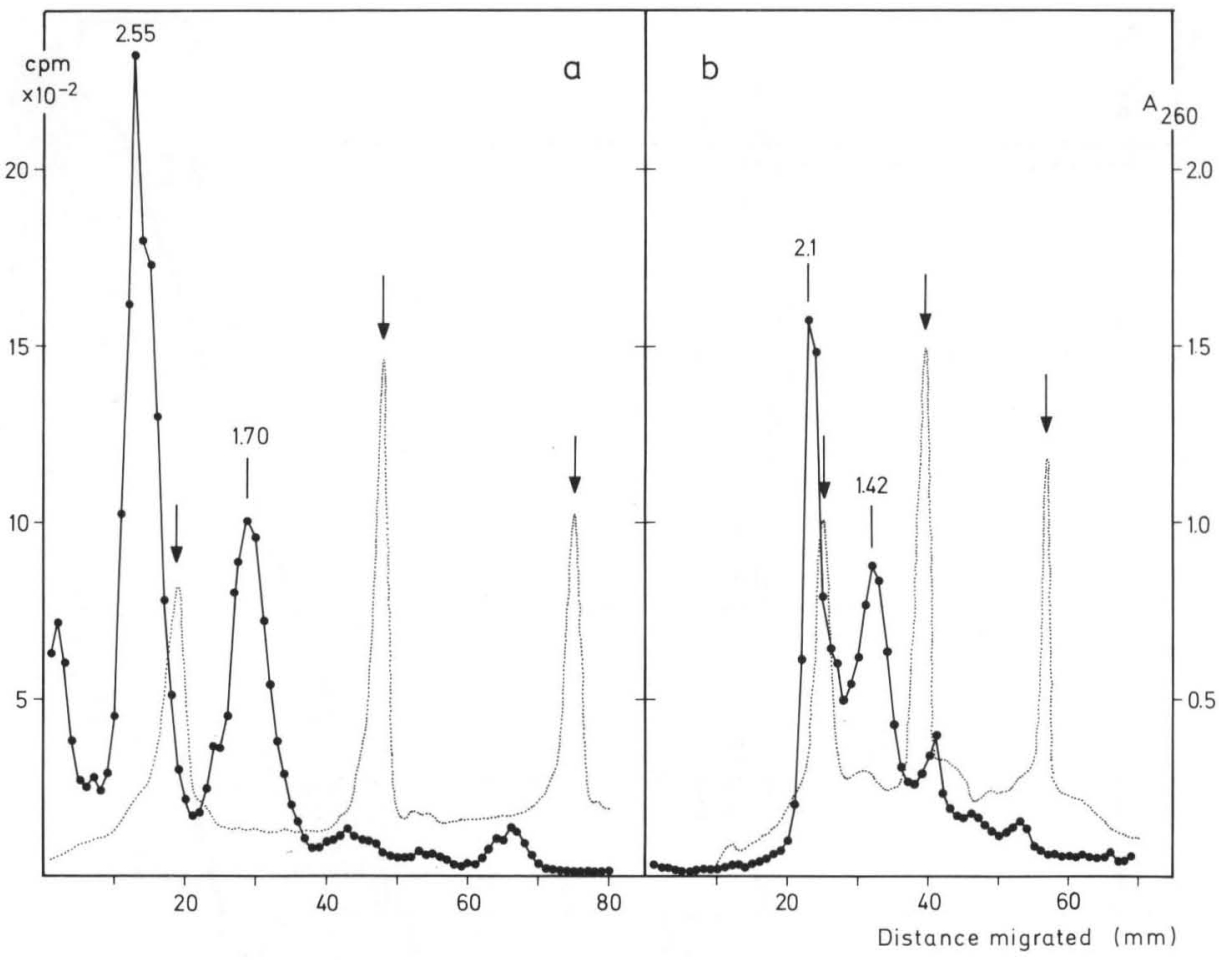

Fig. 10a and b. Gel electrophoretic separation of radioactively labeled RNA extracted from 36 (a) and 35 (b) manually isolated nuclei of lampbrush stage oocytes of Xenopus laevis (2-nu) as revealed in $2.4 \%$ aqueous polyacrylamide gel (a) and 3-7\% exponential polyacrylamide gel in formamide (b). The marker RNAs (arrows; from left to right: TMV-RNA, 23S and 16S rRNA from $E$. coli) are identified by their UV-absorbance (dotted line). The apparent molecular weights of the rRNA precursor species are indicated in million daltons (for discussion see text)

at the moment since for RNAs larger than ca. $1.3 \times 10^{6}$ an exact relationship between the true molecular weight and values obtained by either electron microscopic measurements of partly denatured molecules (cf. Highton and Beer, 1963) or electrophoresis under denaturing and non-denaturing conditions has not yet been established.

\section{Discussion}

Our results show a marked heterogeneity of the lengths of repeating units of rDNA in the oocytes of Xenopus laevis which can be demonstrated in transcriptionally active nucleoli by electron microscopy. The present data basically confirm and extend our previous findings based on a much lower number of preparations and animals (Scheer et al., 1973). Although in the histograms of most preparations a predominant repeat unit size class (mean length either ca. $3.3 \mu \mathrm{m}$ or $3.8 \mu \mathrm{m}$ ) can be recognized as a more or less pronounced maximum, 
size differences among different repeating units are highly significant. The range of repeating unit lengths observed with this method corresponds to that reported by Wellauer et al. (1974, 1976a, b; cf. also Morrow et al., 1974) from analyses of rDNA fragments obtained by cleavage with the restriction endonuclease EcoRI. The frequently noted maximum of a total repeating unit length of about $3.8 \mu \mathrm{m}$ in our analyses may reflect the predominance of a rDNA repeat unit of ca. $7.6 \times 10^{6}$ molecular weight reported by Wellauer et al. (1974, $1976 \mathrm{a}, \mathrm{b})$ in different shipments of toads. Moreover, our histograms of the sizes of the repeating units in transcribed nucleolar chromatin from various animals suggest the existence of distinct subclasses that occur at variable frequencies in different animals. The major subclasses noted in our study seem to correspond to some of the size classes of rDNA units of Xenopus laevis and $X$. muelleri determined by gel electrophoresis of cleavage fragments obtained by treatment with restriction enzyme (Morrow et al., 1974; Wellauer et al., 1974, 1976a, b). From our finding that the degree and the pattern of heterogeneity of isolated amplified nucleoli attached to the nuclear envelope is indistinguishable from that observed in spread preparations of total nuclear contents of the same animal, it is further clear that this heterogeneity exists in the amplified rDNA units, in accord with the studies of rDNA cleavage patterns after treatment with EcoRI nuclease (references quoted above). In contrast to the notion of Wellauer et al. (1976b), however, we conclude from the present data that size heterogeneities of repeating units can also exist within individual amplified rDNA molecules, besides a large number of amplified nucleolar strands that consist of rather homogeneous repeating units. Such intra-axial heterogeneity is hardly explained by an amplification mechanism which involves starting units which contain only one pre-rRNA gene (for discussion see Wellauer et al., 1976b). The existence of different rDNA units in the same amplified molecule seems to be compatible with the widely accepted concept that amplification takes place via a "rolling circle" mechanism (Hourcade et al., 1973; Rochaix et al., 1974; Bakken, 1975; Buongiorno-Nardelli et al., 1976) only if one allows for multigenic rDNA circles containing different units in the initial steps of the replicative process. Adjacent repeating units of different sizes have recently also been described in the amplified rDNA of the oocytes of two insect species, Dytiscus marginalis and Acheta domesticus (Trendelenburg et al., 1976, 1977). Moreover, size differences of rDNA repeating units in the same strand (intraaxial heterogeneities) have been noted in spread preparations of nucleoli from primary nuclei of dasycladacean green algae (Spring et al., 1974, 1976; Trendelenburg et al., 1974) and from embryonic cells of Drosophila melanogaster (e.g., Fig. 6 of McKnight and Miller, 1976) and the milkweed bug, Oncopeltus fasciatus (Foe et al., 1976), but in all these cases a non-amplified, chromosomal nature of the specific strand cannot be excluded.

Wellauer and his colleagues $(1974,1976 \mathrm{a}, \mathrm{b})$ have reported that the size differences among rDNA repeating units exclusively reflect differences of the lengths of the specific intercepts of "non-transcribed spacer". Although the exact relationship between the rDNA region containing the sequence for the pre-rRNA and the matrix unit observed in the transcribed nucleolar chromatin is yet not fully understood (for detailed discussion see, e.g., Loening, 1975; 
Franke et al., 1976a; Rungger and Crippa, 1976) the present results strongly support our earlier interpretation (Scheer et al., 1973) that the transcribed regions, i.e. in approximation the matrix units, can also show length differences, even in adjacent repeating units. Whether such differences in matrix unit lengths really correspond to size differences of pre-rRNA molecules, or whether they represent variations of the amounts of material cleaved from the growing pre-rRNA molecule (cf. Franke et al., 1976a), remains to be clarified. In this connection it should again be emphasized that in no eukaryotic cell system the primary product of rDNA transcription has yet been identified. On the contrary, there exist indications that the specific predominant pre-rRNA component, i.e. in amphibia the RNA species with $2.55 \times 10^{6}$ or $2.1 \times 10^{6}$ apparent molecular weight (depending on the specific gel system used for determination; cf. Results; note also figures of 2.74 and $2.81 \times 10^{6}$ molecular weight estimated from contour length measurements in electron micrographs of partially denatured molecules; cf. Wellauer and Dawid, 1974; Schibler et al., 1975) is not the primary transcript (Slack and Loening, 1974; Loening, 1975; Franke et al., 1976a; Rungger and Crippa, 1976).

The results of our experiments with oocytes of the 1-nu mutant illustrate the existence of a great extent of heterogeneity of repeat unit lengths within one nucleolar organizer and amplified derivatives thereof. This indicates that the extent of heterogeneity present in a specific nucleolus organizer can be as large as that of the two different organizers present in the oocytes of normal animals with the genetical 2-nu constitution. This is in accord with the report by Wellauer et al. (1976b) who found significant heterogeneity of the spacer fragments obtained by EcoRI cleavage of rDNA from 1-nu toads.

The distribution of the lengths of the repeating units of rDNA as demonstrated by the analysis of fragments obtained after specific cleavage with restriction endonuclease EcoRI corresponds to that measured directly in the transcribed nucleolar chromatin after dispersion and spreading under various conditions. This strongly supports the view that the rDNA is in B-conformation and in an extended form, i.e. not packed into nucleosomes, in the transcriptionally active chromatin (for detailed discussion see Franke et al., 1976b). The histones which have been found in nucleoli isolated from Xenopus laevis stage II and III oocytes (Higashinakagawa et al., 1976) then would be present either in inactive regions of nucleolar chromatin (as to the changes of transcriptional activity during oogenesis see Scheer et al., 1976b) or would be associated with the DNA in a non-nucleosomal form.

The apparent spacer intercepts of nucleolar chromatin of Xenopus laevis show, at variable frequency, distinct groups of lateral fibrils of increasing lengths which are not continuous with the fibril gradient of the specific following prerRNA matrix unit. Such "prelude complexes" of variable lengths, some of which occupy most of the whole spacer intercept, have been observed in nucleolar chromatin from other organisms and cell types (Scheer et al., 1973; Trendelenburg et al., 1973, 1974, 1976, 1977; Spring et al., 1974; Franke et al., 1976a). Their existence strongly suggests that parts of the apparent spacer region of rDNA are, at least occasionally, transcribed simultaneously with the pre-rRNA genes. Whether their occurrence reflects the "irregular" persistence of products 
of transcription in early regions of transcriptional units of pre-rRNA genes, or whether they represent the transcription of other genes remains open (for detailed discussions see Franke et al., 1976a; Rungger and Crippa, 1976).

Most of the amplified pre-rRNA genes present in the nucleoli of the Xenopus laevis oocytes are obviously arranged in long chromatin strands containing more than ten repeating units. Under preparative conditions that perfectly allow the deposition of single gene units of rDNA on the specimen grid (cf. Trendelenburg et al., 1976, 1977) we found only very rarely short linear or circular units (only three rings containing five and six repeating units, respectively, were encountered among a total of several thousand repeating units evaluated, cf. Miller and Beatty, 1969; in general, rings of nucleolar chromatin were much rarer in oocytes of Xenopus laevis than in those of Triturus alpestris and $T$. cristatus). Therefore, it may be justified to hypothesize that the relatively small circular units of rDNA that have been demonstrated in rDNA amplifying stages of ovary development (Hourcade et al., 1973; Rochaix et al., 1974; Bakken, 1975; Buongiorno-Nardelli et al., 1976) are intermediate stages in the amplification process and represent only a minor fraction of the rDNA containing molecules transcribed during diplotene.

Acknowledgement. We thank Mrs. Signe Mähler for skillful technical assistance and Dr. Andrew Ziemiecki (European Molecular Biology Laboratory, Heidelberg) for reading and correcting the manuscript. The work has been supported by the Deutsche Forschungsgemeinschaft (grant Sche 157/2).

\section{References}

Bakken, A.H.: Replication of amplifying ribosomal deoxyribonucleic acid in rolling circles in Xenopus laevis oocytes. J. Histochem. Cytochem. 23, 463-474 (1975)

Berger, S., Schweiger, H.-G.: An apparent lack of non-transcribed spacers in rDNA of a green alga. Molec. gen. Genet. 139, 269-275 (1975)

Bird, A., Rogers, E., Birnstiel, M.: Is gene amplification RNA-directed? Nature (Lond.) New Biol. 242, 226-230 (1973)

Birnstiel, M., Chipchase, M., Speirs, J.: The ribosomal RNA cistrons. Progr. Nucleic. Acid Res. Molec. Biol. 11, 351-389 (1971)

Brown, D.D., Wensink, P.C., Jordan, E.: A comparison of the ribosomal DNA's of Xenopus laevis and Xenopus mulleri: the evolution of tandem genes. J. molec. Biol. 63, 57-73 (1972)

Buongiorno-Nardelli, M., Amaldi, F., Lava-Sanchez, P.A.: Electron microscope analysis of amplifying ribosomal DNA from Xenopus laevis. Exp. Cell Res. 98, 95-103 (1976)

Dawid, I.B., Brown, D.D., Reeder, R.H. : Composition and structure of chromosomal and amplified ribosomal DNA's of Xenopus laevis. J. molec. Biol. 51, 341-360 (1970)

Dawid, I.B., Wellauer, P.K.: A reinvestigation of $5^{\prime} \rightarrow 3^{\prime}$ polarity in $40 \mathrm{~S}$ ribosomal RNA precursor of Xenopus laevis. Cell 8, 443-448 (1976)

Elsdale, T.R., Fischberg, M., Smith, S.: A mutation that reduces nucleolar number in Xenopus laevis. Exp. Cell Res. 14, 642-643 (1958)

Fellner, P.: Structure of the $16 \mathrm{~S}$ and $23 \mathrm{~S}$ ribosomal RNAs. In: Ribosomes (M. Nomura, A. Tissières, P. Lengyer, eds.), pp. 169-191. Cold Spring Harbor Lab. 1974

Foe, V.E., Wilkinson, L.E., Laird, C.D.: Comparative organization of active transcription units in Oncopeltus fasciatus. Cell 9, 131-146 (1976)

Forsheit, A.B., Davidson, N., Brown, D.D.: An electron microscope heteroduplex study of the ribosomal DNAs of Xenopus laevis and Xenopus mulleri. J. molec. Biol. 90, 301-314 (1974) 
Franke, W.W., Scheer, U., Spring, H., Trendelenburg, M.F., Krohne, G.: Morphology of transcriptional units of rDNA. Exp. Cell Res. 100, 233-244 (1976a)

Franke, W.W., Scheer, U., Trendelenburg, M.F., Spring, H., Zentgraf, H.W.: Absence of nucleosomes in transcriptionally active chromatin. Cytobiologie 13, 401-434 (1976b)

Gariglio, P., Buss, J., Green, M.H.: Sarkosyl activation of RNA polymerase activity in mitotic mouse cells. FEBS Letters 44, 330-333 (1974)

Hagenbüchle, O., Schibler, U., Wyler, T.: Intermolecular renaturation of hairpin loops leads to stable and specific aggregates of 28-S rRNA and precursor rRNAs from Xenopus laevis. Europ. J. Biochem. 60, 73-82 (1975)

Higashinakagawa, T., Wahn, H., Reeder, R.H.: Isolation of ribosomal gene chromatin. Develop. Biol. (1977), in press

Highton, P.J., Beer, M.: An electromicroscopic study of extended single polynucleotide chains. J. molec. Biol. 7, 70-77 (1963)

Hourcade, D., Dressler, D., Wolfson, J.: The amplification of ribosomal RNA genes involves a rolling circle intermediate. Proc. nat. Acad. Sci. (Wash.) 70, 2926-2930 (1973)

Laird, C.D., Wilkinson, L.E., Foe, V.E., Chooi, W.Y.: Analysis of chromatin-associated fiber arrays. Chromosoma (Berl.) 58, 169-190 (1976)

Loening, U.E.: The determination of the molecular weight of ribonucleic acid by polyacrylamide-gel electrophoresis. The effects of changes in conformation. Biochem. J. 113, 131-138 (1969)

Loening, U.E.: The mechanism of synthesis of ribosomal RNA. In: Biochemistry of the cell nucleus; mechanism and regulation of gene expression, Vol. 33 (E.J. Hidvégi, J. Sümegi, P. Venetianer, eds.), pp. 151-157. Amsterdam: North-Holland Publ. Comp. (1975)

Loening, U.E., Jones, K.W., Birnstiel, M.L.: Properties of the ribosomal RNA precursor in Xenopus laevis; comparison to the precursor in mammals and in plants. J. molec Biol. 45, 353-366 (1969)

McKnight, S.L., Miller, Jr., O.L.: Ultrastructural patterns of RNA synthesis during early embryogenesis of Drosophila melanogaster, Cell 8, 305-319 (1976)

Miller, O.L., Bakken, A.H.: Morphological studies of transcription. Acta endocr., Suppl. 168, 155-177 (1972)

Miller, O.L., Beatty, B.R.: Extrachromosomal nucleolar genes in amphibian oocytes. Genetics, Suppl., 61, 134-143 (1969)

Morrow, J.F., Cohen, S.N., Chang, A.C.Y., Boyer, H.W., Goodman, H.M., Helling, R.B.: Replication and transcription of eukaryotic DNA in Escherichia coli. Proc. nat. Acad. Sci. (Wash.) 71, 1743-1747 (1974)

Reeder, R.H., Higashinakagawa, T., Miller, Jr., O.: The $5^{\prime} \rightarrow 3^{\prime}$ polarity of the Xenopus ribosomal RNA precursor molecule. Cell 8, 449-454 (1976)

Reijnders, L., Aalbers, A.M.J., van Kammen, A. : Molecular weights of plant viral RNAs determined by gel electrophoresis under denaturing conditions. Virology 60, 515-521 (1974)

Rochaix, J.D., Bird, A., Bakken, A.: Ribosomal RNA gene amplification by rolling circles. J. molec. Biol. 87, 473-487 (1974)

Rogers, M.E., Klein, G.: Amphibian ribosomal ribonucleic acids. Biochem. J. 130, 281-288 (1972)

Rungger, D., Crippa, M.: The primary ribosomal DNA transcript in eukaryotes. Progr. Biophys. molec. Biol. 31 (in press, 1976)

Scheer, U.: Nuclear pore flow rate of ribosomal RNA and chain growth rate of its precursor during oogenesis of Xenopus laevis. Develop. Biol. 30, 13-28 (1973)

Scheer, U., Franke, W.W., Trendelenburg, M.F., Spring, H. : Classification of loops of lampbrush chromosomes according to the arrangement of transcriptional complexes. J. Cell Sci. 22, 503 $519(1976 \mathrm{a})$

Scheer, U., Trendelenburg, M.F., Franke, W.W.: Transcription of ribosomal RNA cistrons. Exp. Cell Res. 80, 175-190 (1973)

Scheer, U., Trendelenburg, M.F., Franke, W.W.: Effects of actinomycin D on the association of newly formed ribonucleoproteins with the cistrons of ribosomal RNA in Triturus oocytes. J. Cell Biol. 65, 163-179 (1975)

Scheer, U., Trendelenburg, M.F., Franke, W.W.: Regulation of transcription of genes of ribosomal RNA during amphibian oogenesis. J. Cell Biol. 69, 465-489 (1976b)

Schibler, U., Hagenbüchle, Wyler, T., Weber, R., Boseley, P., Telford, J., Birnstiel, M.L.: The arrangement of $18-\mathrm{S}$ and $28-\mathrm{S}$ ribosomal ribonucleic acids within the $40-\mathrm{S}$ precursor molecule of Xenopus laevis. Europ. J. Biochem. 68, 471-480 (1976) 
Schibler, U., Wyler, T., Hagenbüchle, O.: Changes in size and secondary structure of the ribosomal transcription unit during vertebrate evolution. J. molec. Biol. 94, 503-517 (1975)

Slack, J.M.W., Loening, U.E. : 5'-ends of ribosomal and ribosomal precursor RNAs from Xenopus laevis. Europ. J. Biochem. 43, 59-67 (1974)

Speirs, J., Birnstiel, M.: Arrangement of the $5.8 \mathrm{~S}$ RNA cistrons in the genome of Xenopus laevis. J. molec. Biol. 87, 237-256 (1974)

Spohr, G., Mirault, M.-E., Imaizumi, T., Scherrer, K. : Molecular weight determination of animal-cell RNA by electrophoresis in formamide under fully denaturing conditions on exponential polyacrylamide gels. Europ. J. Biochem. 62, 313-322 (1976)

Spring, H., Krohne, G., Franke, W.W., Scheer, U., Trendelenburg, M.F.: Homogeneity and heterogeneity of sizes of transcriptional units and spacer regions in nucleolar genes of Acetabularia. J. Microscopie Biol. Cell 25, 107-116 (1976)

Spring, H., Trendelenburg, M.F., Scheer, U., Franke, W.W., Herth, W. : Structural and biochemical studies of the primary nucleus of two green algal species, Acetabularia mediterranea and Acetabularia major. Cytobiologie 10, 1-65 (1974)

Trendelenburg, M.F., Franke, W.W., Scheer, U.: Frequencies of circular units of nucleolar DNA in oocytes of two insects, Acheta domesticus and Dytiscus marginalis, and changes of nucleolar morphology during oogenesis. Differentiation 7 (in press, 1977)

Trendelenburg, M.F., Scheer, U., Franke, W.W.: Structural organization of the transcription of ribosomal DNA in oocytes of the house cricket. Nature (Lond.) New Biol. 245, 167-170 (1973)

Trendelenburg, M.F., Scheer, U., Zentgraf, H.W., Franke, W.W.: Heterogeneity of spacer lengths in circles of amplified ribosomal DNA of two insect species, Dytiscus marginalis and Acheta domesticus. J. molec. Biol. 108, 453-470 (1976)]

Trendelenburg, M.F., Spring, H., Scheer, U., Franke, W.W.: Morphology of nucleolar cistrons in a plant cell, Acetabularia mediterranea. Proc. nat. Acad. Sci. (Wash.) 71, 3626-3630 (1974)

Wellauer, P.K., Dawid, I.B. : Secondary structure maps of ribosomal RNA and DNA. I. Processing of Xenopus laevis ribosomal RNA and structure of single-stranded ribosomal DNA. J. molec. Biol. 89, 379-395 (1974)

Wellauer, P.K., Dawid, I.B., Brown, D.D., Reeder, R.H.: The molecular basis for length heterogeneity in ribosomal DNA from Xenopus laevis. J. molec. Biol. 105, 461-486 (1976a)

Wellauer, P.K., Reeder, R.H.: A comparison of the structural organization of amplified ribosomal DNA from Xenopus mulleri and Xenopus laevis. J. molec. Biol. 94, 151-161 (1975)

Wellauer, P.K., Reeder, R.H., Carroll, D., Brown, D.D., Deutch, A., Higashinakagawa, T., Dawid, I.B.: Amplified ribosomal DNA from Xenopus laevis has heterogeneous spacer lengths. Proc. nat. Acad. Sci. (Wash.) 71, 2823-2827 (1974)

Wellauer, P.K., Reeder, R.H., Dawid, I.B., Brown, D.D.: The arrangement of length heterogeneity in repeating units of amplified and chromosomal ribosomal DNA from Xenopus laevis. J. molec. Biol. 105, 487-505 (1976b)

Wensink, P.C., Brown, D.D.: Denaturation map of the ribosomal DNA of Xenopus laevis. J. molec. Biol. 60, 235-247 (1971)

Received December 23, 1976/Accepted December 26, 1976 by H. Bauer Ready for press December 27, 1976 